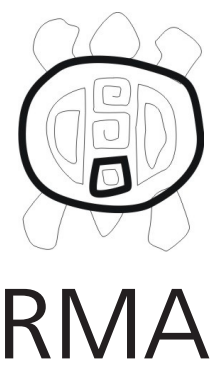

Arqueología

\title{
Arquitectura y paisajes en la localidad arqueológica de Andalhuala (Valle de Yocavil, Catamarca)
}

\author{
Alina Álvarez Larrain
}

Museo Etnográfico "Juan B. Ambrosetti", Facultad de Filosofía y Letras, Universidad de Buenos Aires. E- mail: alinaalvarezlarrain@gmail.com

\begin{abstract}
Resumen
El espacio arquitectónico se constituye como parte del paisaje cultural que participa de lleno en la construcción y reproducción de las prácticas domésticas y rituales y del imaginario colectivo de la comunidad que lo construye y lo habita. La localidad arqueológica de Andalhuala se presenta así como un área que nos permite abordar cómo fue la construcción y el uso del espacio en la vertiente oriental del valle de Santa María o Yocavil, cuyos patrones de asentamiento fueron anteriormente definidos a partir de lo conocido para el flanco occidental. Se discuten aquí las evidencias recuperadas a partir de tareas de prospección y relevamiento arquitectónico en la mencionada localidad. Los resultados obtenidos hasta ahora revelan un panorama complejo de ocupaciones desde los inicios del primer milenio D.C. hasta los finales de los tiempos tardios, abarcando una franja espacial desde los terrenos bajos próximos a cuencas permanentes hasta los pisos inferiores de la Sierra del Aconquija.
\end{abstract}

Palabras clave: Valle de Yocavil; localidad arqueológica de Andalhuala ; sociedades agropastoriles; paisajes arqueológicos; variabilidad de asentamientos.

Architecture and landscape in Andalhuala archaeological locality (Yocavil Valley, Catamarca)

\begin{abstract}
The architectural space is set up as part of the cultural landscape is fully involved in the construction and reproduction of domestic and ritual practices and the collective imagination of the community that builds and inhabits it. The Andalhuala archaeological locality is thus presented as an area that allows us to consider what was the construction and use of space on the eastern slope of the valley of Santa Maria or Yocavil whose patterns of settlement were previouly identified from the known to the western flank. We discuss here the evidence recovered from prospecting and surveying architectural in the mentioned locality. The results so far indicate a complex picture of occupations since the beginning of the first millennium D.C. until the final of the late times, comprising a strip space from the lowlands near permanent basins to the lower floors of the Sierra del Aconquija.
\end{abstract}

Keywords: Yocavil Valley; Andalhuala archaeological locality; agropastoral societies; archaeological landscape; variability of settlements.

El valle de Santa María o Yocavil ha sido objeto de interés arqueológico desde mediados del siglo XIX, cuando comienza a ser expoliado por saqueadores $y$ coleccionistas y visitado por viajeros con interés científico, quienes registrarán las numerosas ruinas arqueológicas emprendiendo los primeros trabajos de excavación, principalmente de cementerios (Scattolin 2000, 2003). Como plantean Tarragó y Scattolin (1999), esta larga historia de exploración y depredación arqueológica y la falta de una investigación sistemáticamente orientada a encontrar los vestigios de las sociedades agropastoriles "pre santamarianas", proyectaron una imagen de "tierra baldía" antes del siglo X D.C. (Sensu Scattolin 2000).

Hoy el valle de Yocavil evoca en nuestra mente los sitios del período Tardío de alta visibilidad y arquitectura compleja (Ambrosetti 1897; González 1954; Nastri 1997- 98; 2001;
Raffino 1991; Tarragó 1987; 1995; 2000). Mientras que en la vertiente occidental se han podido registrar al menos siete grandes poblados: Tolombón, Pichao, Quilmes, Fuerte Quemado, Las Mojarras, Rincón Chico y Cerro Mendocino (Tarragó 1995: 226), la vertiente oriental no ha recibido tanta atención, estudiándose principalmente dos sitios: Loma Rica de Shiquimil (LRS) y Loma Rica de Jujuil (LRJ). Nastri (2001: 33) plantea que la LRS se convirtió en el paradigma de lo que había que registrar: instalaciones con buena conservación arquitectónica, aglutinamiento de recintos y posición estratégica en altura sobre mesetas de paredes escarpadas que proporcionan un límite natural al asentamiento y al sitio arqueológico. Esto se pudo deber a la dualidad del valle a nivel geomorfológico dado que mientras la vertiente Oeste presenta un paisaje fisiográfico bien definido de cerro, ladera y llanura pedemontana (Tarragó 1995: 225), 
relieve que tuvo su correlato en la interpretación de las instalaciones prehispánicas, el Este del valle se presenta como un paisaje de complicadas formas.

Así, los patrones de asentamiento tardíos de la vertiente oriental de Yocavil fueron definidos por comparación a partir de lo conocido para el Oeste. De esta manera la contraparte oriental del patrón tipo Rincón Chico definido para el Cajón, fue el patrón tipo Loma Rica (Tarragó 1995: 231- 232). El patrón Rincón Chico se define por cuatro tipos de instalaciones dentro de lo que se considera un mismo asentamiento: a) instalaciones en la cumbre (Pukara); b) unidades asociadas en la ladera (núcleo urbano); c) unidades complejas de canchón y estructuras anexas en el bajo (Pueblo Viejo) y d) campos de cultivo adyacentes al río (Nastri 2003). Este modelo intrasitio se articula con otro a escala mayor donde los grandes centros poblados establecen relaciones jerárquicas entre sí, estando divididos en centros de primer y segundo orden (Tarragó y Nastri 1999). Este patrón de asentamiento se enriqueció luego al incorporar los puestos de actividades específicas instalados en la sierra (Nastri 1997- 98; Nastri et al. 2002). Por su parte, el patrón Loma Rica se define principalmente por la presencia de dos poblaciones gemelas (LRS y LRJ) (Tarragó 1995). Debido a las diferencias en tamaño, densidad de las construcciones y organización de los espacios públicos y de circulación, la LRS ocuparía el primer rango en la jerarquía de asentamientos. Con respecto a otros tipos de instalaciones, se propuso una vinculación con núcleos aglomerados de menor orden y con instalaciones agrícolas cercanas a cuencas permanentes, cuyas buenas condiciones hídricas habrían permitido su ocupación desde épocas tempranas, así como su posterior intensificación agrícola, siendo las poblaciones allí asentadas las posibles proveedoras de alimentos para los núcleos políticos (Tarragó y González 2005: 138).

Más allá de esta propuesta, y debido a la falta de datos más acabados, poco se avanzó en entender cómo las poblaciones hicieron uso de este espacio tan complejo a lo largo del tiempo y cómo fueron las articulaciones entre asentamientos de distinto orden hacía los tiempos tardíos. Se suma a esta problemática la ausencia de trabajos en los pisos de alturas que permitan contar con un conocimiento más global de esos patrones de usos del espacio. Scattolin y colaboradoras han mostrado la relevancia de estudiar los faldeos del Aconquija dada la presencia de puestos de pastores o refugios de altura (Scattolin 2001; Scattolin y Albeck 1994; Scattolin y Korstanje 1994). El estudio sistemático y continuado de la localidad arqueológica de Andalhuala, como sector representativo del Este de Yocavil, puede ayudar a clarificar las diversas problemáticas planteadas comenzando a delinear cómo fue la ocupación prehispánica del oriente. Así, los objetivos específicos de este trabajo son:

- Dar a conocer las primeras prospecciones realizadas en la localidad arqueológica de Andalhuala que dieron cuenta de nuevos yacimientos.

- Describir las características constructivas de la arquitectura hallada y de la cerámica de superficie asociada a la misma (usados también como marcadores cronológicos).

- Comenzar a delinear cómo fue la construcción y el uso del espacio en el Sudeste de Yocavil durante la etapa agroalfarera.

\section{Paisajes arqueológicos: repensando el espacio en arqueología.}

Las investigaciones arqueológicas han mostrado desde sus comienzos interés por el espacio como una variable relevante para entender el desenvolvimiento de las actividades humanas. No obstante, será con los estudios de la Ecología Cultural y luego con los trabajos de Willey (1953), que se encare la localización y el mapeo de sitios arqueológicos a escala regional, yendo más allá del estudio de los yacimientos aislados para establecer las relaciones de complementariedad de un conjunto de sitios a partir de las diferentes funcionalidades que cada uno presenta dentro de un sistema cultural mayor (Orejas 1991:199; Trigger 1992: 266). Posteriormente, la búsqueda de parámetros de mayor objetividad generó la aplicación de modelos como el Site catchment analysis, la Teoría de los Lugares Centrales de Christaller y la Regla del Rango Tamaño, surgiendo una nueva Arqueología Espacial, cuyo comienzo se puede establecer con las obras Spatial Archoeology de Clarke (1977) y Análisis espacial en arqueología de Hodder y Orton (1990). Sin embargo el espacio seguirá siendo el medioambiente entendido como mero escenario natural o contenedor de la vida social.

En la actualidad los estudios sobre patrones de asentamiento han adoptado perspectivas más amplias incorporando cuestiones de historia, percepción, acción humana e identidad (Anschuetz et al. 2001). Nuevos enfoques ven el espacio como una dimensión más compleja y activa, surgiendo en arqueología propuestas relacionadas a los paisajes arqueológicos que ven al mismo como una creación dinámica, donde personas y paisajes se influyen y crean mutuamente (Kusch et al. 2001).

Criado (1995: 78) repiensa al espacio no como "entidad física ya dada, estática y mera ecología" sino como "construcción social, imaginaria, en movimiento continuo y enraizada en la cultura". Se suple así una visión del espacio donde éste es visto como algo fijo e inerte, con un concepto contextual del espacio inseparable de un sistema de saber de una sociedad en un momento y lugar determinado (Criado Boado 1993: 11). El paisaje será entendido desde esta perspectiva como un producto sociocultural creado por la objetivación de la acción social, tanto de carácter material como imaginario, sobre el medio espacial. Así, el paisaje no es sinónimo de medioambiente, sino el producto de un proceso 
sociocultural, en constante construcción y reproducción (Anschuetz et al. 2001). Precisamente, el espacio entendido como paisaje presenta múltiples dimensiones: 1. espacio como entorno natural gracias al cual las poblaciones se sustentan; 2. espacio como entorno social o medio construido por las personas a partir de sus actividades diarias, sus creencias y valores y 3 . espacio como entorno pensado o medio simbólico cargado de significado (Anschuetz et al. 2001: 161; Criado Boado 1999:5). Estas tres dimensiones analíticas del paisaje deben ser abordadas de forma complementaria, pudiendo priorizarse alguna de ellas según avanza el análisis de una región.

A su vez, la consideración del paisaje como un constructo sociocultural implica reconocer la posibilidad de hallar distintos paisajes arqueológicos en un mismo espacio geográfico producto de distintas racionalidades (Criado Boado 1995). La reconstrucción de los paisajes arqueológicos es posible porque las actividades humanas del pasado han dejado una impronta detectable cuya solidez nos permite estudiar esos paisajes tiempo después de que las acciones que les dieron origen hayan cesado (Ingold 1993: 162).

La arquitectura prehispánica, reflejo de las acciones sociales pretéritas, forma parte de las tecnologías para construir el espacio. La Arqueología de la Arquitectura la define como la manipulación antrópica de un espacio a través de técnicas constructivas que varían en el tiempo. Así, la arquitectura está vinculada tanto con el entorno físico como con la sociedad que la genera, estando su forma directamente relacionada con los códigos de uso y concepción del espacio y con los esquemas de pensamiento de una sociedad (Mañana Borrazás et al. 2002: 14). La casa y el espacio construido son mecanismos físicos que reflejan, pero también crean, un mundo, imponiendo esquemas de organización y conducta social (Rapoport 1972: 68). Se llega así a un espacio arquitectónico que se constituye como parte del paisaje cultural que participa de lleno en la construcción y reproducción de las prácticas domésticas y rituales y del imaginario colectivo de la comunidad que lo construye y lo habita.

Teniendo en cuenta estas premisas teóricas comenzamos el estudio de la localidad arqueológica de Andalhuala, partiendo del estudio de su espacio arquitectónico, con el objetivo futuro de poder reconstruir los distintos paisajes sociales que se sucedieron en el tiempo.

\section{Contexto mayor: el valle de Yocavil}

El valle de Yocavil (Catamarca y Tucumán) se sitúa dentro de la región valliserrana del Noroeste argentino. El nivel inferior del valle se encuentra entre los 1.500- 2000 msnm y se enmarca entre dos importantes cordones montañosos. Hacia el Oeste la Sierra del Cajón o Quilmes se eleva unos $3500 \mathrm{~m}$, estando su flanco oriental conformado por laderas de pendientes pronunciadas y extensos conos de deyección de relieve más atenuado. Hacia el Este se levanta la Sierra del Aconquija, con una elevación máxima

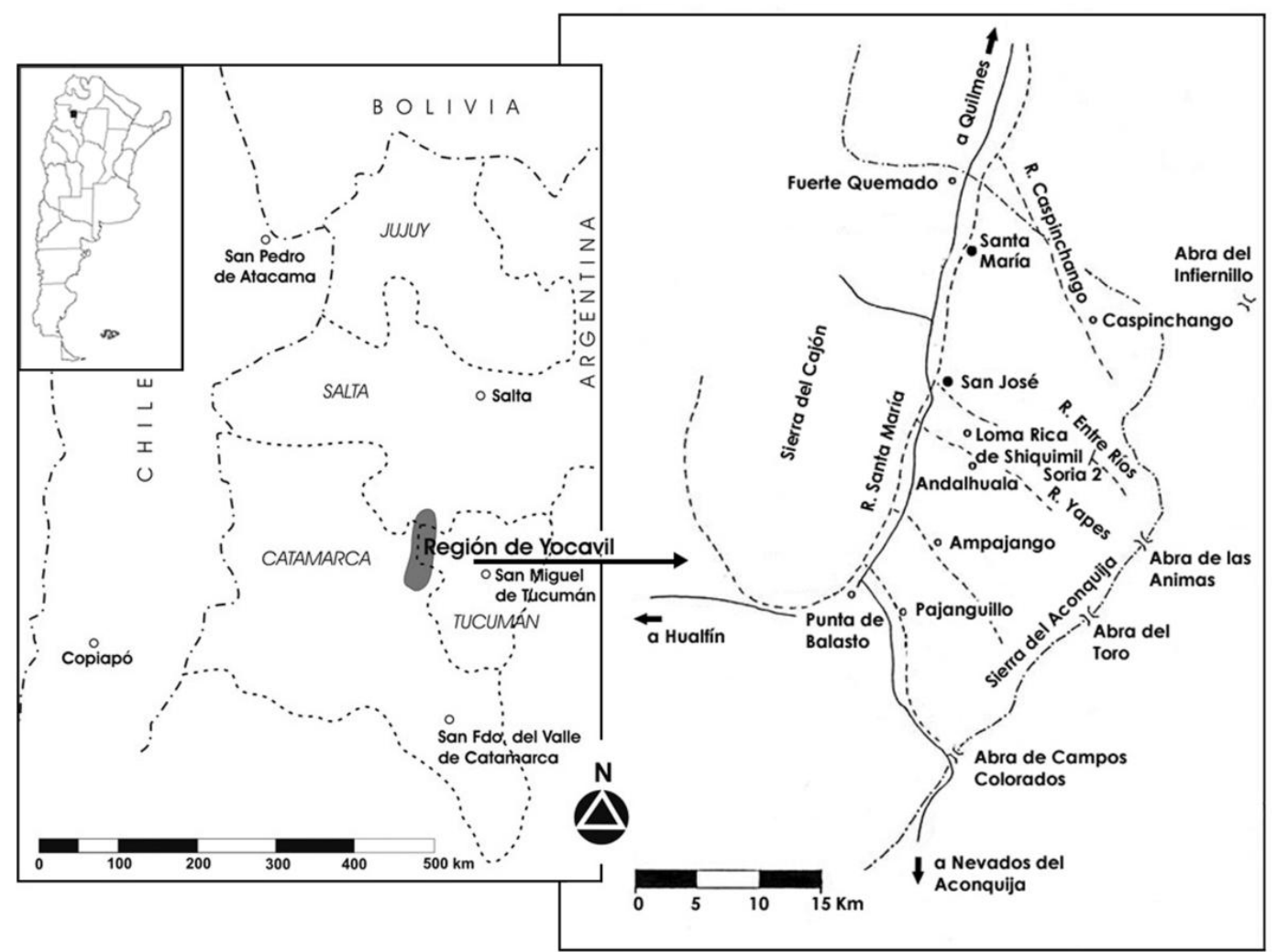

Figura 1. Mapa del valle de Yocavil con la ubicación de la Localidad arqueológica de Andalhuala. 
de 5500 msnm descendiendo hacia la zona de Amaicha y el Abra del Infiernillo (Tucumán), siendo esta falla la que lo separa de las Cumbres Calchaquíes.

El valle sólo puede ser considerado una unidad en sentido cartográfico, mientras que su geomorfología permite apreciar variaciones considerables. La vertiente oriental, sector que aquí nos ocupa, presenta un relieve sumamente quebrado. Sobre las formaciones sedimentarias plegadas del terciario (Plioceno - Grupo Santa María), se encuentran los niveles aterrazados cuaternarios, entre los cuales han sido labrados los valles transversales a la estructura del macizo del Aconquija de dirección NNE- SSO (Ruiz Huidobro 1972). LoS relieves terciarios, pero principalmente las formaciones cuaternarias, revisten una importancia fundamental dado que las instalaciones, tanto actuales como prehispánicas, se encuentran en íntima relación con ellas.

En la interacción entre dichas formaciones y la instalación humana juega como factor substancial el sistema de drenaje del valle de Yocavil. El río Santa María, principal curso hídrico, corre por un amplio lecho fluvial de entre 35 y 45 km, siendo una cuenca permanente de caudal escaso durante el estiaje. Por su parte, la mayoría de las cuencas tributarias se presentan como intermitentes, estando secas la mayor parte del año. La excepción la constituyen los ríos orientales que descienden desde la cumbre del Aconquija (Amaicha, Caspinchango, Entre Ríos, Yapes, Andalhuala, Ampajango, Pajanguillo, entre otros) (Ruiz Huidobro 1972). Estos ríos corren en sentido general $\mathrm{E}-\mathrm{O}$, formando verdaderos oasis en un entorno semiárido. Precisamente, la población actual del valle de Yocavil se encuentra fuertemente ligada a los principales cursos de agua y asentada en pueblos de carácter agrario.

\section{La localidad arqueológica de Andalhuala}

Las cuencas orientales que corren entre los niveles aterrazados también albergan instalaciones actuales en sus playas aluvionales y terrenos bajos. Una de ellas es la localidad de Andalhuala ubicada a unos $25 \mathrm{~km}$ al SE de la ciudad de Santa María. Enmarcada entre los ríos Yapes al Norte y Andalhuala al Sur, se encuentra dividida en tres sectores (Bolsi 1967). El sector Sur, conocido como Andalhuala del Bajo, lo constituye el río Andalhuala y su planicie aluvial encajonada entre altas barrancas, donde se puede observar una estrecha franja de terrenos cultivados. El sector central, Ilamado Andalhuala del Alto, lo compone el trecho de planicie aluvial abandonada en sentido N- S, que existe entre el río Yapes y el nuevo curso del río Andalhuala. Aquí se encuentra el pueblo propiamente dicho (escuela, locutorio, cuartel de policía), rodeado de áreas cultivadas. El sector Norte, conocido como Andalhuala La Banda, es una zona de fincas que se encuentran instaladas en las planicies aluviales de los ríos Yapes y Zampay. Inmediatamente al N de La Banda se levanta la Meseta de Andalhuala, uno de los niveles aterrazados con significancia arqueológica.

El régimen de propiedad de los campos es privado. Los principales cultivos son el maíz, la vid, los nogales y otros árboles frutales. La actividad agrícola no utiliza maquinaria para el laboreo de los campos y depende del agua de riego, habiendo en Andalhuala distintas represas que almacenan el agua y numerosas acequias que la reparten entre los campos.

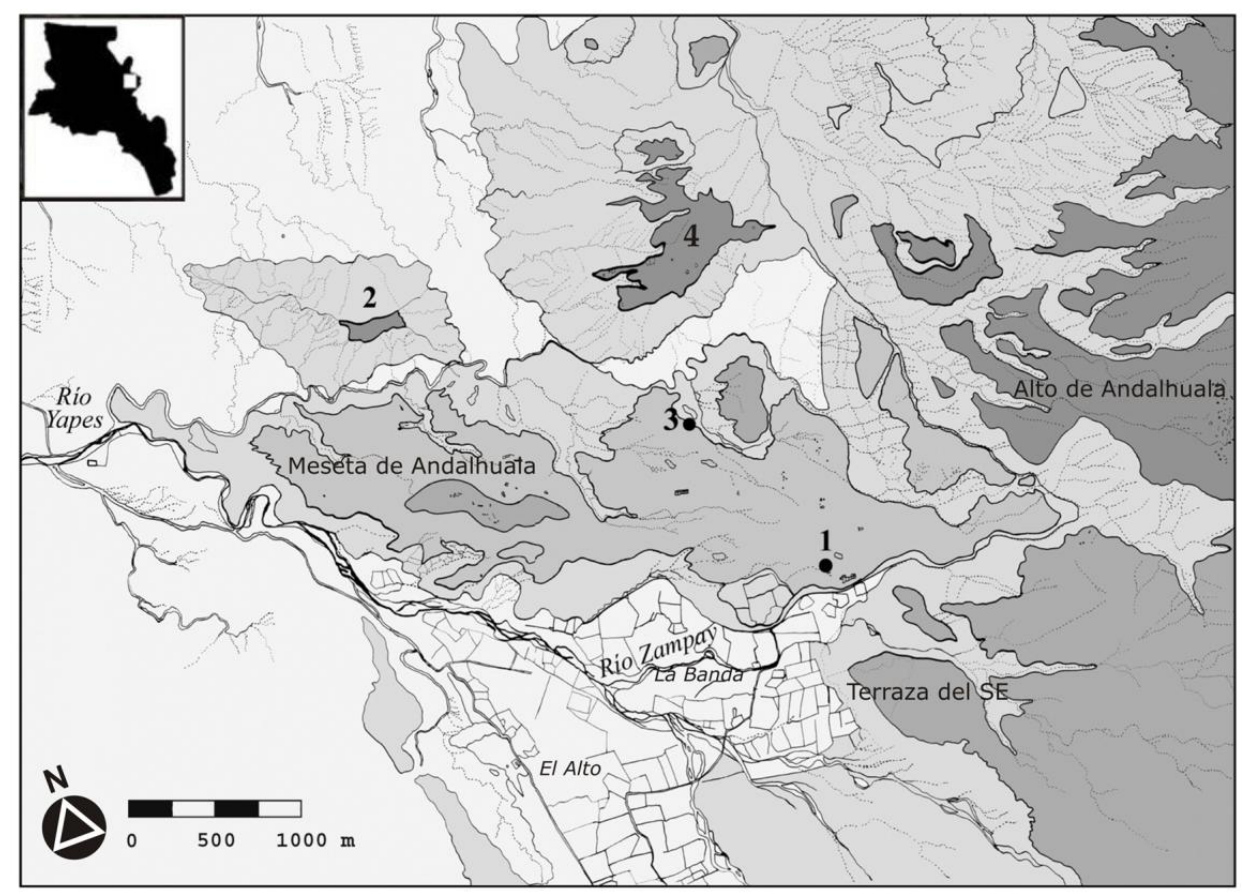

Figura 2. Calco del Norte de la localidad arqueológica de Andalhuala realizado a partir de aerofotografía: 1. sitio Soria 2; 2. Loma Rica de Shiquimil; 3. sitio Loma Alta y 4. formación Loma Alta (Modificado de Palamarczuk et al. 2007, fig. 1). 
La localidad actual de Andalhuala tiene su correlato en la localidad arqueológica de Andalhuala. El concepto de localidad arqueológica, pocas veces explicitado, es utilizado aquí para hacer referencia a una zona de estudio con interés arqueológico, definida por límites arbitrarios que se corresponden con cierta división del espacio actual, es decir lo que se reconoce cartográficamente y/o por la población actual como Localidad de Andalhuala.

La localidad arqueológica de Andalhuala ha sido visitada desde los comienzos de los estudios en Yocavil. Una de las primeras excursiones fue encarada por Liberani y Hernández (1877), quienes mencionan la LRS y una necrópolis al Sur de la misma que fue excavada recuperando varias urnas funerarias ${ }^{1}$. Reproducen también un petroglifo de la "Puerta de Andalguala" y uno al pie de la LRS en el "Río Seco", no dando más datos. Methfessel también visitará esta zona por los años 1887-89, recuperando varias urnas santamarianas (Chiappe 1965: 25). Posteriormente, Ten Kate (1894: 334) visitará Andalhuala recuperando objetos de los cuales no especifica su naturaleza ni contexto de hallazgo. Boman (1908), menciona petroglifos de Andalhuala, ilustrando algunos ejemplares. Por su parte, Bruch en su trabajo de 1911, dedica un capítulo a "Loma Rica, Andalhuala y Ampajango", donde menciona los petroglifos documentados previamente por Liberani y Hernández. Quiroga (1931:71- 75) también registrará petroglifos en Andalhuala, no brindando su localización.

El principal referente arqueológico, vinculado a la problemática plateada más arriba, es la LRS². Los visitantes de la LRS han sido muchos a lo largo del tiempo, siendo los trabajos encarados por Weiser los primeros en levantar un plano del poblado, posteriormente corregido por Tarragó y equipo (Tarragó et al. 1988, Weiser 1923-24). La LRS se presenta como un asentamiento en patrón aglomerado sobre una meseta. La misma se levanta 100 $\mathrm{m}$ sobre el nivel de base y presenta una cumbre horizontal de $320 \times 120 \mathrm{~m}$, conformando un área habitacional de 2,45 ha, con 189 recintos. Los muros de los mismos fueron construidos con grandes rodados formando muros dobles con relleno de ripio y arcilla, utilizando para los cimientos y sobrecimientos piedras de mayor tamaño. El ancho de algunos muros, cercano a los 3 ó 4 m, permitió el uso de los mismos como vías de transito dentro del asentamiento. Los únicos sectores despejados de la cumbre lo constituyen las dos plazas que se abren en las esquinas NO y NE y los espacios irregulares que quedan delimitados entre los conjuntos de viviendas (Tarragó et al. 1988). En los años 50, cuando Rex González visita la

\footnotetext{
1 Tarragó et al. 1988 ponen en duda que la Loma Rica descripta por Liberani y Hernández sea efectivamente la de Shiquimil dado que el plano y las estructuras que describen, como las murallas circulares, no fueron posteriormente registradas en la misma.

${ }^{2}$ La LRS debe su nombre a la localidad vecina de Entre Ríos, anteriormente conocida como Shiquimil o Chiquimí. Nosotros la consideramos dentro de la localidad arqueológica de Andalhuala dada su mayor proximidad con la misma.
}

zona, menciona que las elevaciones al Sur de la LRS se encuentran cubiertas de pircas, algunas correspondiendo a partes de recintos y otras pudiendo ser muros de contención o andenes de siembra. Caracteriza a estos muros como de doble hilera con relleno, asimilándolos constructivamente con los recintos en la cima de la LRS (González 1954: 81).

En la década del 60, dentro del marco de un proyecto regional de la Universidad Nacional del Litoral sobre Yocavil (Cigliano 1960), se recorre nuevamente la localidad de Andalhuala (Arocena y Carnevali 1960). El primer sitio mencionado será Bajo de Andalhuala, que según las autoras sería el mismo sector excavado por Methfessel y posteriormente por Weiser, y que según referencias de González (1954) correspondería a los terrenos al pie de la LRS. Las autoras hablan de abundantes restos de pircados donde realizan cuatro sondeos estratigráficos, dos de ellos dando como resultado niveles superiores con alfarería santamariana y niveles inferiores con cerámica gris lisa pulida, proponiendo así una primera ocupación temprana de los portadores de esta última y un posterior asentamiento tardío. Un segundo sitio lo denominan Andalhuala Los Andenes, por la presencia de andenes y cuadros de cultivo. Por último, las autoras describen el sitio Andalhuala El Cerro. Según describen, el mismo se levanta $400 \mathrm{~m}$ sobre el nivel de base en un desprendimiento lateral del Aconquija, separado por una estrecha garganta. Sobre un faldeo a $200 \mathrm{~m}$ de altura, se registraron al menos tres conjuntos de recintos intercomunicados de planta rectangular asociados de a dos por medio de un pasillo y numerosos recintos aislados en mal estado de conservación. Las unidades se escalonan siguiendo la pendiente natural, separadas entre sí por muros de contención. La técnica constructiva de los muros (pirca y doble hilera con ripio intermedio) y la cerámica (Santa María Bicolor, SM Tricolor y San José), indicaron una ocupación "santamariana". Según informaran a las autoras, en la cima se hallarían casas, corrales y muros que no llegaron a relevar (Arocena y Carnevali 1960: 55). Lamentablemente, la publicación no cuenta con datos o cartografía precisa que de cuenta de la localización de estos tres yacimientos.

Tras un lapso de 40 años, el Proyecto Arqueológico Yocavil realiza nuevos acercamientos. En el año 1987, Caviglia realiza una prospección en el extremo septentrional de la Meseta de Andalhuala con el objetivo de detectar fuentes de agua y áreas agrícolas relacionadas al asentamiento en la LRS. Durante esta prospección constató la presencia de andenes y canchones de cultivos así como recintos habitacionales, sitio que fue denominado Loma Alta (Copello 1991; González y Tarragó 2005). En el año 2002 se efectúa una prospección pedestre en el sector meridional de la misma meseta, observándose líneas de piedra que conformaban aterrazados y estructuras de uno

\footnotetext{
${ }^{3}$ El nombre del sitio se debe a la formación tipo meseta que se levanta al Norte, conocida por los lugareños como Loma Alta.
} 
o más recintos de plantas circulares y cuadrangulares. Se encara entonces un sondeo exploratorio en el ángulo conformado por dos líneas de piedras en un área aterrazada, con el objetivo de obtener fechados que permitieran datar las estructuras agrícolas. Se da así con muros de piedra que no eran visibles en superficie (Palamarczuk et al. 2007). Dada la riqueza artefactual de este contexto, denominado Soria 2, nuevas excavaciones fueron realizadas durante los años 2004, 2005, 2006, 2009 y 2010 a cargo de Romina Spano ${ }^{4}$.

Las excavaciones en Soria 2 dejaron al descubierto dos recintos adosados ( $R 1$ y $R 2$ ). El R1 es una estructura de 8 por $8 \mathrm{~m}$, abierta hacia el Oeste dado que no se localizó aun un muro que lo cierre en esa dirección. El R2 es una estructura de planta subcuadrangular de la cual se han destapado tres de sus muros. Los muros son simples, con excepción del muro compartido que se presenta como muro doble con relleno, con mampuestos de aristas redondeadas, de tamaño uniforme. La piedra bola utilizada, materia prima de la zona, fue seleccionada y trabajada para que la cara interna de los muros se presente plana, dando a las construcciones una apariencia prolija. Las esquinas de ambos recintos son curvas y conforman ángulos cercanos a los $90^{\circ}$ (Álvarez Larrain et al. 2009).

A partir de la presencia de rasgos y estructuras (pozo con residuos, fogón y agujeros de postes), la posición horizontal de los artefactos y el ensamble de los fragmentos cerámicos de mayores dimensiones, se pudo determinar la presencia de un piso de ocupación bien definido (Palamarczuk et al. 2007). Investigaciones posteriores (Belotti López de Medina 2007; Carbonelli 2009; Spano 2008) confirmaron la presencia de un contexto doméstico. Spano ha planteado que los recintos excavados estarían conformando una unidad compuesta, hasta el momento integrada por dos recintos, constituyéndose como una unidad residencial doméstica. El R1 podría estar correspondiendo a un patio donde se ha constatado la realización de múltiples actividades tales como, la cocción y el consumo de alimentos evidenciados por la presencia de un fogón, la abundancia de ollas ordinarias con presencia de termoalteración y de restos óseos fragmentados. Del análisis de la cerámica hallada se desprende que la misma fue utilizada tanto en el ámbito cotidiano en tareas de consumo y servicio de alimentos y bebidas como posteriormente en eventos funerarios como contenedores de niños (Spano 2008). Ambos recintos fueron el espacio de distintas modalidades de entierros de infantes planteando la cuestión de la reutilización de las estructuras y el espacio doméstico en el tiempo y la construcción de la memoria colectiva (Álvarez Larrain et al. 2009: 378). Soria 2 constituye hoy una de las evidencias de ocupación más temprana del Sudeste de Yocavil, con un fechado radicarbónico que lo ubica en el $1940 \pm 80$ AP (LP-1541) (Álvarez Larrain et

\footnotetext{
${ }^{4}$ Actualmente las investigaciones en Soria 2 se encuentran insertas en el marco de su tesis doctoral.
}

al. 2009), 53 cal A.C. - 342 cal D.C. (2 sigma- Curva de calibración ShCal04) (McCormac et al. 2004). ${ }^{5}$

\section{Nuevas prospecciones}

A partir de un trabajo de teledetección sobre el Sudeste de Yocavil (Álvarez Larrain 2009a; b), se realizó una primera aproximación a la localidad de Andalhuala en marzo de 2008. Se planteó así la prospección de tres sectores: a) la Meseta de Andalhuala (terraza fluvial baja), b) la terraza fluvial alta que se levanta al Este de la LRS y la Loma Alta, llamada aquí Alto de Andalhuala y c) los terrenos bajos hacia el SE de la Meseta de Andalhuala, separados por el río Zampay. El criterio seguido fue la elección de aquellas zonas que a partir de las aerofotografías ofrecían buenas posibilidades de hallazgo de estructuras. En la Meseta de Andalhuala y los terrenos bajos al SE, dada la complejidad de su registro en superficie, se seleccionaron sectores puntuales, mientras que en el Alto se pudo realizar un barrido más exhaustivo. Por cuestiones de tiempo, también se optó por registrar en principio aquellas estructuras que tuvieran buena visibilidad. Las estructuras detectadas se dibujaron a mano alzada, se marcaron sus ubicaciones con GPS y se registraron y fotografiaron las principales características.

Durante la prospección se procedió a recolectar cerámica de superficie para establecer una asignación temporal tentativa de las estructuras. Para la caracterización de los fragmentos alfareros se tuvieron en cuenta una serie de atributos morfológicos, tecnológicos y decorativos, como el tipo de pasta (grado de compactación e inclusiones), la cocción, el tratamiento de la superficie, la técnica decorativa y los elementos de diseño en base al modelo de planilla Excel y el código para el análisis de fragmentos cerámicos propuesto por Piñeiro (1997). Como referencia se tuvieron en cuenta los tipos tardíos definidos para el valle (Marchegiani 2008; Marchegiani y Grieco 2007; Marchegiani et al. 2009; Perrotta y Podestá 1978). Para la cerámica potencialmente temprana, se recurrió a la observación de la cerámica de Soria 2 y a la comparación con cerámica temprana de otros sitios del valle (Bugliani 2008).

\section{Meseta de Andalhuala}

La Meseta de Andalhuala, superficie aproximada de 250 ha, presenta numerosos vestigios arqueológicos en distintos grados de preservación, que vuelven a esta superficie un palimpsesto complejo de ocupaciones. El sector que se prospectó en esta instancia correspondió a un total aproximado de 17, 7 ha. El grado de deterioro de las estructuras en superficie hizo que nos focalizáramos en aquellas estructuras con mejor visibilidad, registrándolas por sectores según su hallazgo.

En el sector 1 (S $26^{\circ} 51^{\prime} 39,6^{\prime \prime}-0$ 6 $\left.66^{\circ} 02^{\prime} 21,1^{\prime \prime}\right)$, pudieron

${ }^{5}$ Nuevos fechados se encuentran en proceso de análisis y discusión. 

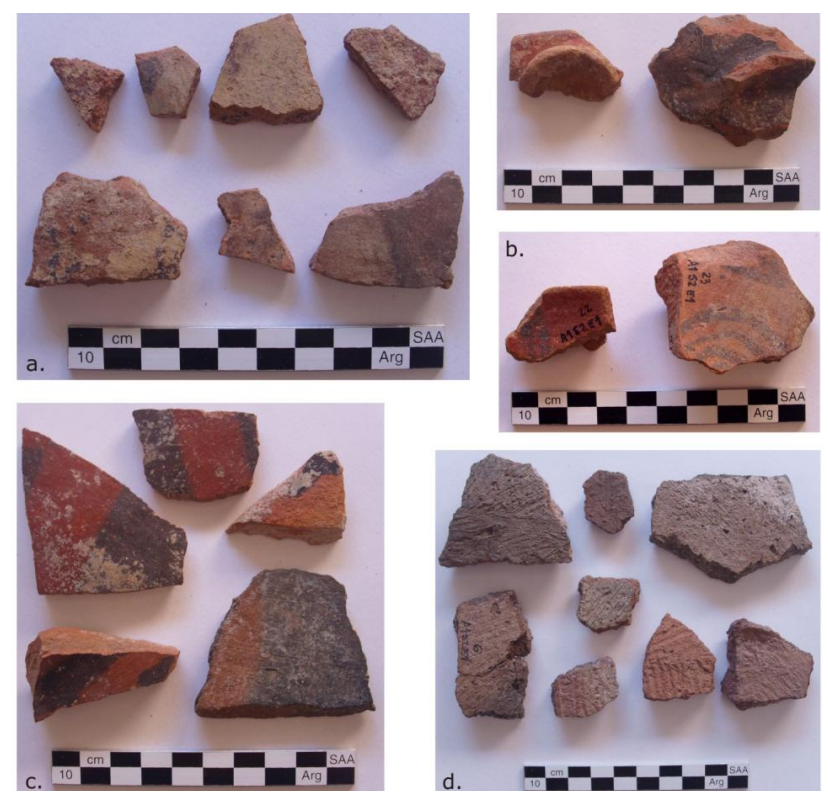

Figura 3. Fragmentos cerámicos recuperados del sector 2 de la Meseta de Andalhuala. a. fragmentos Santa María; b. fragmentos Alisado N/R de piezas abiertas con asas otomorfas; c. Fragmento Alisado N/R y d. Fragmento Peinados C/ Baño.

observarse líneas de piedras, con una disposición paralela y a una distancia entre las mismas entre el metro y los dos metros. No se encontró cerámica en este sector. En el sector 2 (S $26^{\circ} 51^{\prime} 32,24^{\prime \prime}$ - O 66 $06^{\circ} 21,8^{\prime \prime}$ ) se registró un gran recinto de planta subrectangular de 19 x $13 \mathrm{~m}$. El muro 1 presentó una curvatura siguiendo el filo del aterrazado, delimitado por una pequeña cuenca de escurrimiento. Los muros son de pirca simple, con la excepción del muro 2 y el muro 5 que son dobles con relleno. La cerámica encontrada presenta fragmentos asignables a tiempos tardíos: Santa María Indeterminado, Peinado con baño y Alisado Negro/Rojo de los cuales dos fragmentos con presencia de asas otomorfas y decoración interna, se asemejan a Pucos Loma Rica y algunos fragmentos con decoración negra sobre el fondo rojo, sin decoración interna, se asemejan a piezas Shiquimil Geométrico (Figura 3, Tabla 1).

En el sector 3 (S $26^{\circ} 51^{\prime} 29,6^{\prime \prime}$ - O 66 02' 22'), cruzando la cuenca de escurrimiento, se registraron dos recintos de planta cuadrangular sobre una pequeña loma, conformando una unidad asociada a partir de un vano.
El recinto 1, en mejor estado de conservación, mide unos $6 \mathrm{~m}$ de lado. Los muros son dobles con relleno y mortero. En algunos sectores mejor preservados del sobrecimiento se observan bloques de gran tamaño. Al recinto 2, de planta subcuadrangular, se accede por una abertura de $0,80 \mathrm{~m}$. Los pocos fragmentos alfareros recuperados en esta estructura responden a Alisado Indeterminado de pasta compacta con la excepción de un fragmento Santa María Indeterminado (Tabla 1). El hallazgo de esta unidad compuesta permitió tomar la coordenada geográfica del sitio Loma Alta, registrada por Caviglia en 5 sectores tal como se transcribe a continuación (Copello 1991).

En el sector A, observó un "canchón" cuadrangular con lados redondeados y dos pequeños recintos circulares adosados. Hacia el NE, sobre una pendiente del terreno, registró tres "andenes" que seguían las curvas de nivel, presentando subdivisiones transversales. El sector B presentó un gran "canchón" de planta trapezoidal de más de $50 \mathrm{~m}$ de lado. Uno de sus lados tenía una abertura y un recinto de planta cuadrangular inscripto en su interior de 13 m de lado, al cual a su vez, se adosaba en su interior otro recinto de planta cuadrangular de 3,5 $\mathrm{m}$ de lado. Del lado opuesto, en la esquina Sudeste observó un recinto semicircular con un mortero en su interior. A este "canchón" se adosaba otro de aproximadamente $100 \times 50$ m, quedando entre ambos un desnivel de 0,50 $\mathrm{m}$. El sector $\mathrm{C}$ presentaba amontonamientos de piedras, posible resultado del despedre del terreno para el cultivo; un pequeño recinto de planta subcuadrangular y dos sistemas de líneas de piedras paralelas separadas entre sí por 2,5 m aproximadamente, posibles "andenes de cultivo". Hacia la parte alta del sector $C$ observó dos muros de contención, presentando uno de ellos un recinto de planta circular adosado. A pocos metros de los mismos se encontraba un recinto subrectangular o trapezoidal de unos $15 \mathrm{~m}$ de largo que presenta inscripto en su interior otro recinto de planta cuadrangular de unos $5 \mathrm{~m}$ de lado. El sector $D$, presentó un recinto rectangular de dimensiones parecidas al anterior. Por último, el sector E corresponde a la unidad compuesta por dos recintos de planta cuadrangular registrados por nosotros. Los estilos alfareros que observara Caviglia respondieron a tipos locales tardíos e Inka Provincial apuntando a una ocupación santamariana y posterior (González y Tarragó 2005).

\begin{tabular}{lccccc}
\hline & $\begin{array}{c}\text { Meseta And. } \\
\text { Sec. 2 }\end{array}$ & $\begin{array}{c}\text { Meseta And. } \\
\text { Sec 3. R2 }\end{array}$ & $\begin{array}{c}\text { Meseta And. } \\
\text { Sec. 4. R1 }\end{array}$ & $\begin{array}{c}\text { Meseta And. } \\
\text { Sec. 4. R2 }\end{array}$ & Total \\
\hline 1. Santa María Indet. & 8 & 1 & - & 1 & 10 \\
2. Peinado con baño (no comp) & 9 & - & 1 & - & 10 \\
3. Peinado con baño (comp) & 3 & - & - & - & 3 \\
4. Alisado Negro/ Rojo & 6 & - & - & 2 & 8 \\
5. Alisado Negro/ Marrón & 1 & - & - & - & 1 \\
6. Alisado Indet. Comp. & 10 & 5 & - & - & 15 \\
7. Pulido Negro Grabado & 1 & - & - & - & 1 \\
8. Indeterminado & 3 & - & 1 & 3 & 51 \\
\hline Total & 41 & 6 & - & - & 3 \\
\hline
\end{tabular}

Tabla 1. Fragmentos cerámicos recuperados en la Meseta de Andalhuala. 1 - 4 cerámica tardía; 7 cerámica pre- tardía; 5,6 y 8 indeterminado. 


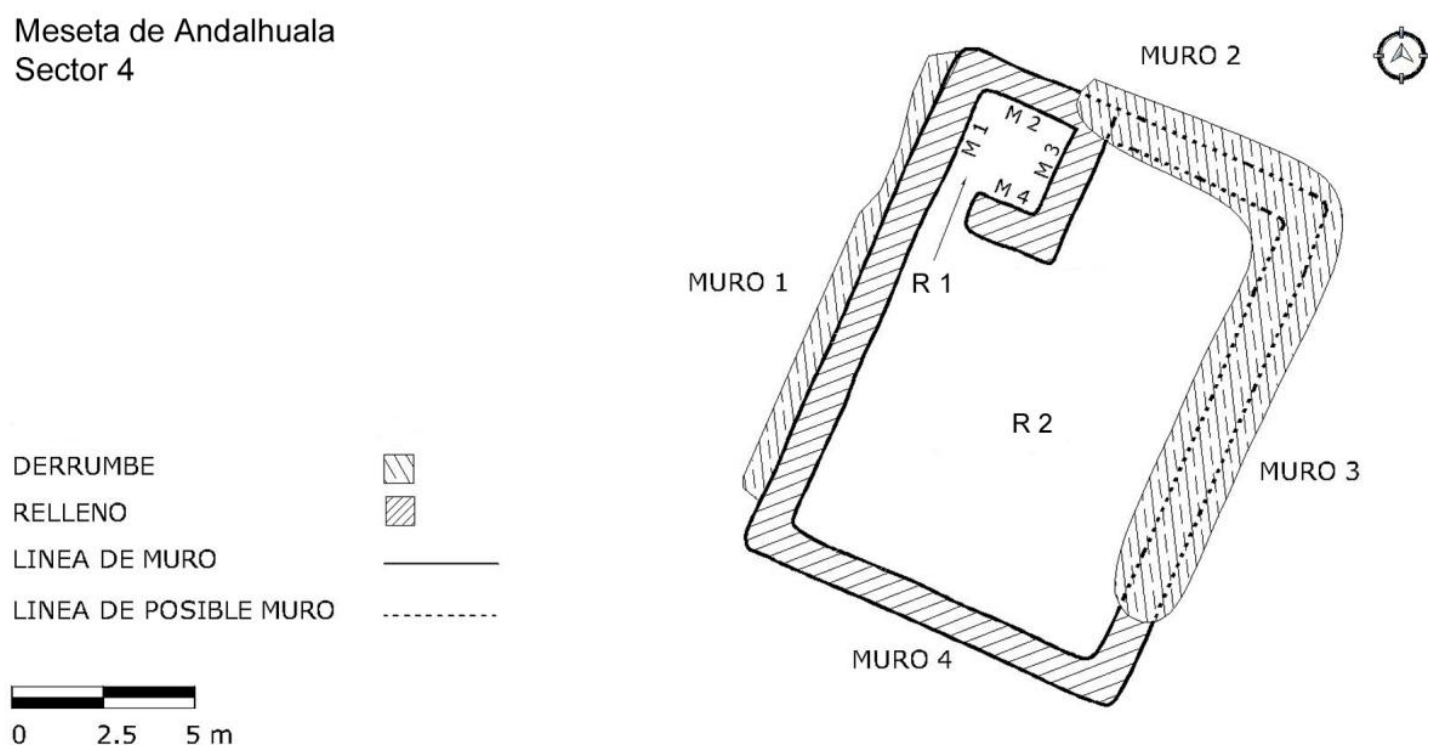

Figura 4. Recinto rectangular con recinto menor inscripto en su interior registrado en el sector 4 de la Meseta de Andalhuala.

Siguiendo con nuestra prospección, en el sector 4 (S $\left.26^{\circ} 51^{\prime} 29,5^{\prime \prime}-066^{\circ} 02^{\prime} 27,9^{\prime \prime}\right)$, se registraron dos recintos asociados (Figura 4). El recinto menor, de planta cuadrangular, cuenta con muros de unos $3 \mathrm{~m}$ de lado, llegando a medir hasta 0,70 y 0,84 m de altura. Este recinto se encuentra inscripto dentro de uno mayor, presentando el muro 4 una abertura que da al interior de la misma. El recinto 2 de planta rectangular, mide 13 x 9 m de lado. Los muros de ambos recintos son muros dobles con relleno de mampuestos sin acomodar, aunque se aprecia una selección de rodados de igual tamaño. La cerámica hallada es escasa. En el R2 se encontraron tres fragmentos, uno Santa María Indeterminado y dos fragmentos de bases Alisado Negro/Rojo, semejantes a bases de pucos Loma Rica (Tabla 1).

El último sector (S $26^{\circ} 51^{\prime} 35,5^{\prime \prime}$ - O $\left.66^{\circ} 02^{\prime} 29,2^{\prime \prime}\right)$ se encuentra ubicado sobre una pequeña loma que se levanta sobre el nivel actual de la terraza. En la parte más alta de la misma, de superficie estrecha, se observó una pequeña estructura de muro simple y planta circular de 1,34 m de diámetro (Figura 5). No se pudo recuperar cerámica en superficie.

\section{Alto de Andalhuala}

Denominamos a esta terraza Alto de Andalhuala dada que es la elevación más importante de la zona. La cima de la terraza, de unas 246 ha, se presentó como una superficie horizontal, cortada por quebradas que dificultaban su prospección. Aquí se hallaron dos concentraciones de fragmentos cerámicos no asociados a estructuras (C1 - C2). La primera concentración fue desenterrada en una ligera cárcava excavada en la tierra húmeda, haciendo suponer que los fragmentos estaban redepositados. Diecisiete fragmentos remontados corresponden a un puco Pulido Negro Grabado. El tipo de tratamiento de la superficie, la presencia de un friso con decoración geométrica de escalonados con línea de relleno por grabado y el grosor de la pasta indican que se trata de cerámica pre- tardía. Junto a esta pieza se levantaron además un fragmento Pulido Gris de pasta compacta semejante a la cerámica temprana del valle y un fragmento Alisado Negro/ Rojo cuya decoración en el interior y el exterior de la pieza se asemeja a los pucos Shiquimil Geométrico. La segunda concentración sólo presentó tres fragmentos alfareros. Dos de ellos corresponden a un fragmento de pie de compotera, forma característica de los tiempos Hispano- Indígenas y un fragmento Alisado Negro/Rojo con decoración en ambas caras (posible puco Loma Rica o Shiquimil Geométrico) (Tabla 2).

En el sector $1\left(\mathrm{~S} 26^{\circ} 51^{\prime} 42,1^{\prime \prime}-\mathrm{O} 66^{\circ} 01^{\prime} 29,8^{\prime \prime}\right)$ se registró un recinto de planta circular de $2,40 \mathrm{~m}$ de diámetro de muro doble con relleno y mortero de 50 a $60 \mathrm{~m}$ de ancho. Este recinto no presenta ninguna abertura y su superficie interna se encuentra elevada respecto al nivel exterior. La cerámica recuperada no fue diagnóstica (Tabla 2). En el sector 2 (S $26^{\circ} 51^{\prime} 47^{\prime \prime}$ - O 66 01' 29,5') se registró otro recinto de planta subcircular de entre 2

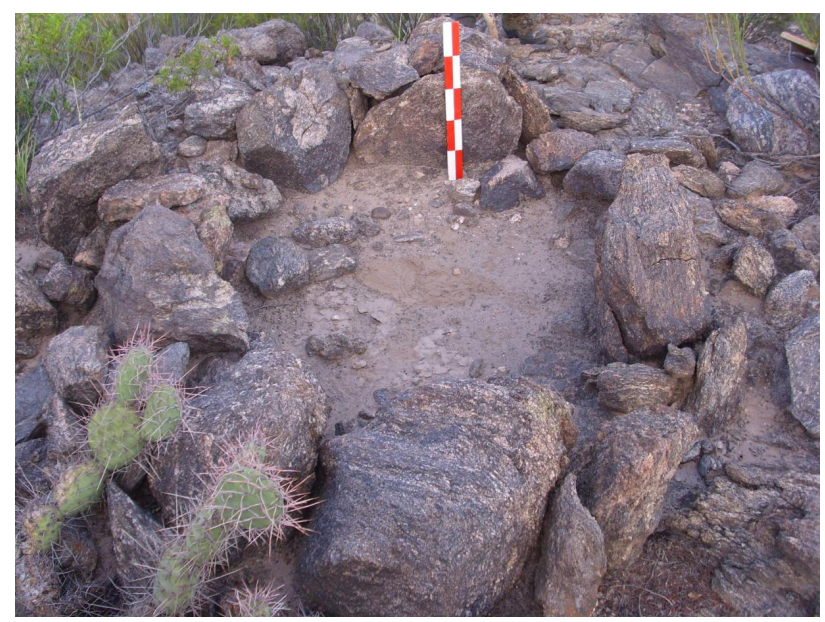

Figura 5. Estructura circular registrada sobre promontorio natural en la Meseta de Andalhuala. 
y $3 \mathrm{~m}$ de diámetro. Los muros parecen ser simples de mampuestos no acomodados. El recinto presenta una abertura delimitada por dos pequeñas jambas y una superficie por encima del nivel exterior (Figura 6). Una segunda estructura registrada en este sector ( $\mathrm{S} 26^{\circ} 51^{\prime}$ $\left.45,4^{\prime \prime}-066^{\circ} 01^{\prime} 25,8^{\prime \prime}\right)$ es un recinto de $10,50 \times 13,40 \mathrm{~m}$ de planta irregular y muros simples. Uno de los muros se encuentra recostado sobre una curva de nivel de la terraza (el piso del recinto se presenta por debajo), estando su esquina delimitada por un peñasco. Los restantes muros se presentan como una sola hilada de piedras. No se encontró cerámica de superficie en este sector.

\section{Terraza al SE del Zampay}

Los terrenos bajos que se encuentra al SE del río Zampay se presentan muy alterados por la gran depositación de sedimentos y la presencia de bloques pétreos de gran tamaño. Aquí se prospecto un área equivalente a 9,5 ha. En el sector 1 (S $26^{\circ} 52^{\prime} 12,6^{\prime \prime}$ - O 66 01' 56,7') se registraron tres estructuras (Figura 7). La primera de ellas se trata de un posible recinto de planta subcuadrangular que conserva sólo la primera hilada de piedras de un aparente muro simple. Esta estructura tiene 4,40 x 6,20 m de lado. El muro 1 presenta a su vez una abertura de 0,78 $\mathrm{m}$ que da hacia un pasillo conformado por una segunda línea de muro paralela a 1,5 m. Hacia el Norte de estas estructuras y separada por una senda que atraviesa toda la terraza, se observó una tercera estructura. Uno de sus muros se presenta como un muro doble con relleno de más de $2 \mathrm{~m}$ de longitud, por el contrario los muros 2 y 3 parecen ser muros simples. La esquina Noroeste de la estructura presenta un enorme bloque rocoso de casi $5 \mathrm{~m}$ de diámetro. La cerámica recuperada fue definida como Alisado Marrón/Anaranjado de pasta no compacta, paredes finas, cocción oxidante y abundante mica, cerámica semejante a la recuperada en el contexto de Soria 2 (Spano com. per.). Otro fragmento recuperado, Alisado Negro/Ante, también responde a cerámica pretardía (Tabla 3). En un sector bajo cercano al río se pudo registrar una gran estructura de 53,70 m de longitud y más de $1 \mathrm{~m}$ de ancho que serpentea por la terraza en sentido NO-SE (S $26^{\circ} 52^{\prime} 11,6^{\prime \prime}$ - O 66 01' 59,8').

En el sector 2 (S $26^{\circ} 52^{\prime} 08,9^{\prime \prime}$ - O 66 $\left.06^{\circ} 56^{\prime \prime}\right)$, a una cota más elevada que el anterior, se registraron 4 recintos adosados de los que se conservaba 1 ó 2 hiladas. Las plantas de estas estructuras son sumamente irregulares y en desniveles. Las dimensiones del R1 de planta

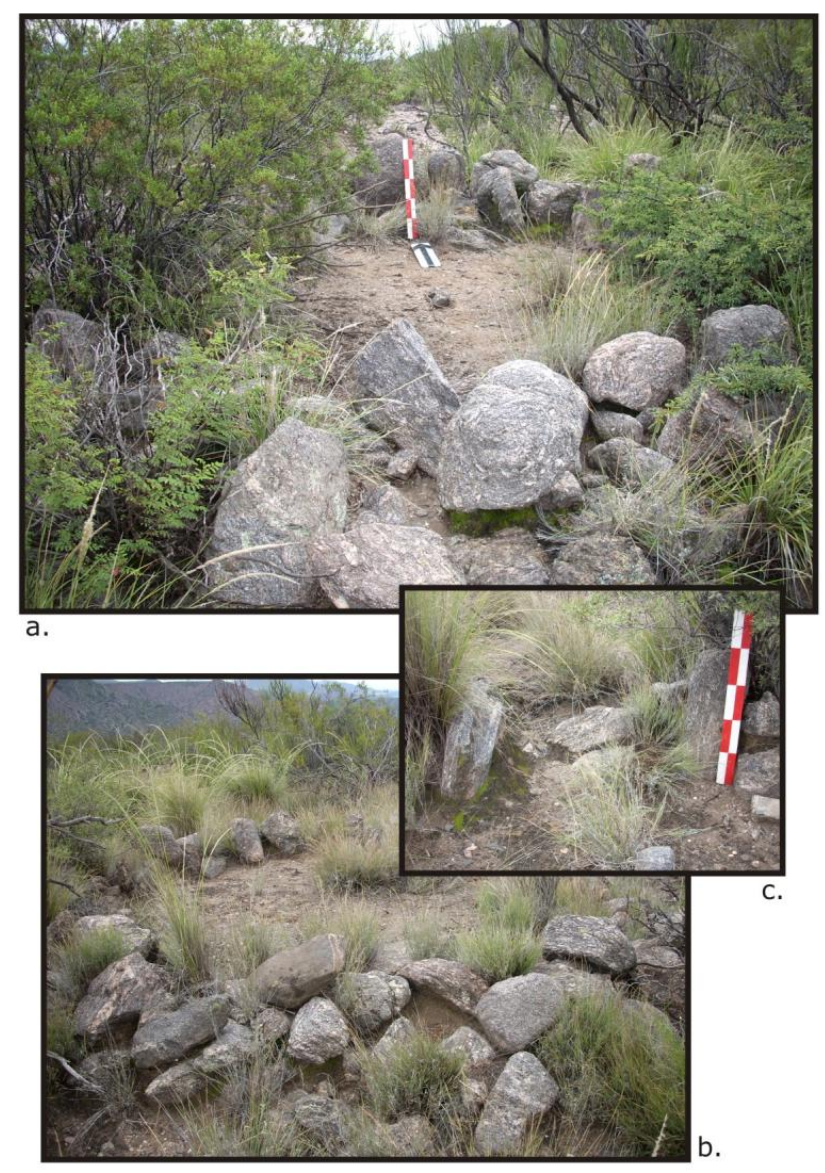

Figura 6. Recintos circulares registrados en Alto de Andlahuala. a. Recinto del sector 1 ; b. Recinto del sector 2; c. abertura del recinto del sector 2 delimitada por dos pequeñas jambas.

subrectangular son: $5,50 \times 8,80 \mathrm{~m}$. El R2 de planta subcuadrangular mide: 6,70 x 5,50 m. El R3 por su parte mide: $10 \times 4,80 \mathrm{~m}$ y el $\mathrm{R} 4$ de menores dimensiones unos $2,90 \times 3,85 \mathrm{~m}$. En los cuatro recintos se pudo hacer recolección de superficie (Tabla 3). El conjunto fino, si bien constituye una muestra pequeña, presenta tipos pulidos asociados a los tiempos tempranos ${ }^{6}$. Dos fragmentos Alisado Negro Grabado también parecen responder a cerámica pre- tardía (Figura 8).

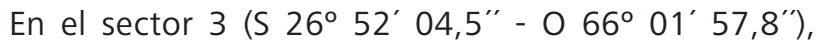
pudieron registrarse dos estructuras. La primera de ellas se presentó como una estructura en " $U$ ", dado que su muro Sur estaba ausente, pudiendo haber sido un recinto de planta cuadrangular de unos 2,30 m de lado

6 Los tipos Pulidos en tonalidades del ante al gris y gris oscuro/ negro, de pastas compactas, han sido registrados en los sitios de la Falda del Aconquija (Bugliani 2008).

\begin{tabular}{lcccc}
\hline & Alto And. C1 & Alto And. C2 & Alto And. Sec. 1 Est.1 & Total \\
\hline 1. Alisado Negro/ Rojo & 1 & 1 & & 2 \\
2. Alisado Indet. (no comp) & 8 & 1 & 2 & 9 \\
3. Pulido Negro Grabado & 9 & & & 11 \\
4. Pulido Gris & 1 & 1 & 2 & 1 \\
5. Hispano Indigena & 19 & 3 & 24 \\
\hline Total & & & 2 & 1 \\
\hline
\end{tabular}

Tabla 2. Fragmentos cerámicos recuperados en Alto de Andalhuala. 1 y 5 cerámica tardía; 3 y 4 cerámica pre- tardía; 2 indeterminado. 


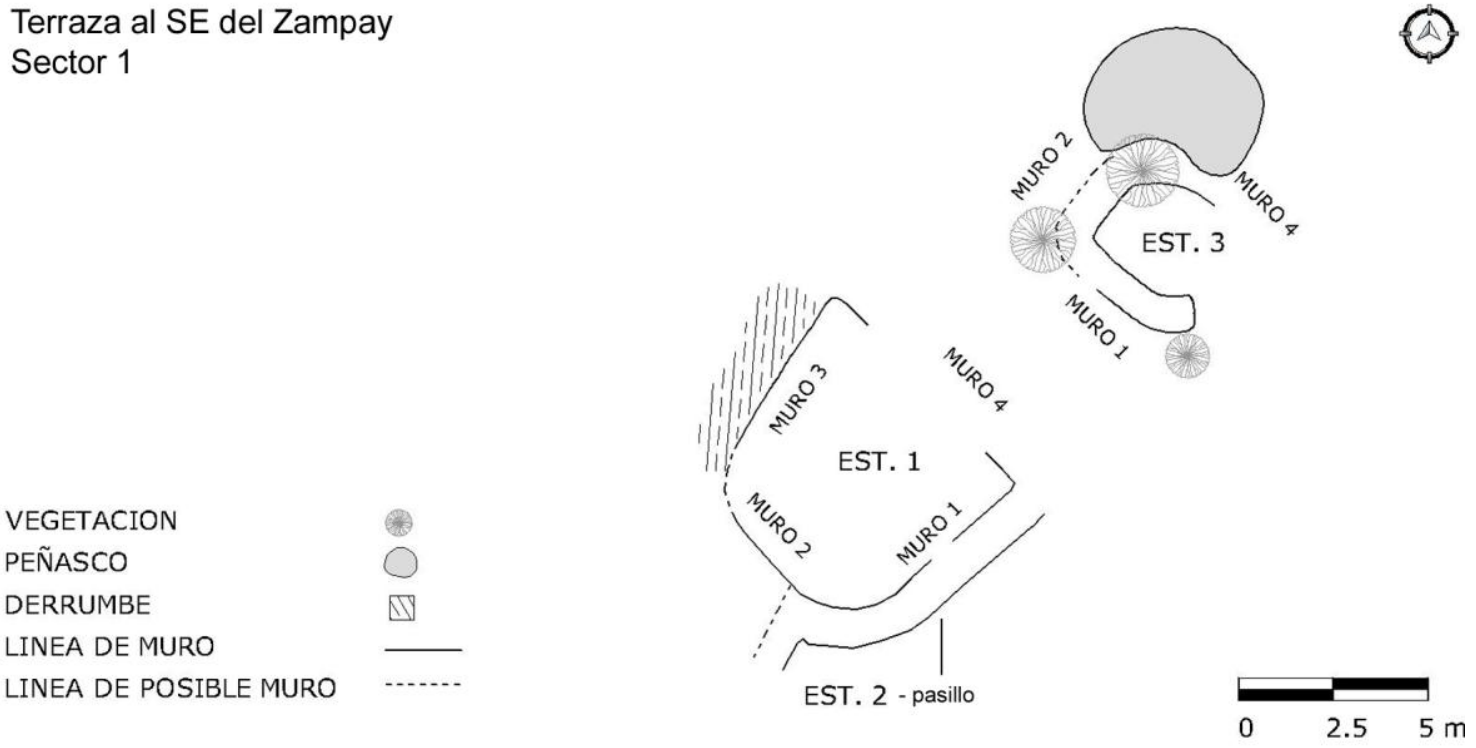

Figura 7. Estructuras subcuadrangulares registradas en el sector 1 de la terraza baja al SE del río Zampay.

(Figura 9). Los muros son dobles con relleno y mortero. Los mampuestos no parecen estar acomodados pero se observa una selección de bloques de tamaño regular y bloques de mayor tamaño para los sobrecimientos. La cerámica predominante es Alisada Indeterminada (Tabla 3). La siguiente estructura es un recinto de planta circular de 6,28 m de diámetro de muro doble con relleno, con mampuestos de mayor tamaño en las hiladas inferiores. Este recinto oscila entre los $0,20 \mathrm{~m}$ y $0,70 \mathrm{~m}$ de altura $\mathrm{y}$ cuenta con una abertura de 0,74 $\mathrm{m}$ hacia el Sudeste. Los fragmentos diagnósticos son un fragmento Pulido Gris, semejante a la cerámica de Soria 2 y dos fragmentos Alisados Negro/Rojo, semejantes a la alfarería tardía (Tabla 3).

\section{Reconstruyendo los paisajes arqueológicos de Andalhuala}

Los tiempos tempranos...

El sitio Soria 2 en la Meseta de Andalhuala refleja la elección de las terrazas de baja altura (2100- 2200 msnm) para la instalación humana desde los tiempos tempranos. Su superficie plana de considerable extensión y la cercanía a los recursos, principalmente el hídrico, la volvieron un lugar con un uso prolongado desde los inicios de la etapa agroalfarera.

Como ya mencionáramos, Spano (2008) ha planteado la presencia de un contexto doméstico para Soria 2. Los trabajos no son concluyentes faltando aún la completa delimitación de las formas de las estructuras y la determinación de su instalación en el contexto mayor de la terraza ${ }^{7}$, sin embargo, a la hora de avanzar una posible interpretación de Soria 2 desde la perspectiva del uso del espacio mayor, creemos que el mismo podría responder a un sistema de asentamiento donde las unidades domésticas, áreas de residencia familiar, se encontraran dispersas en terrenos propicios para la actividad agropecuaria. Las estructuras registradas en el sector 1 de la terraza baja al SE del Zampay, con plantas subcuadrangulares similares a Soria 2, presencia de cerámica temprana y mismo tipo de instalación, parece

${ }^{7}$ En marzo de 2010 se continuaron las tareas de prospección y relevamiento arquitectónico de la Meseta de Andalhuala y el levantamiento con Estación total de las estructuras cercanas a Soria 2 en el marco de la tesis doctoral sobre la Localidad de Andalhuala (Álvarez Larrain 2009c).

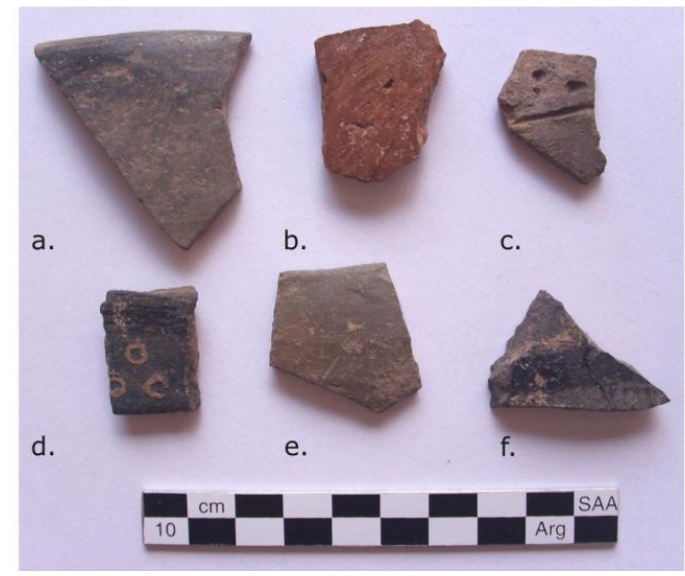

g.
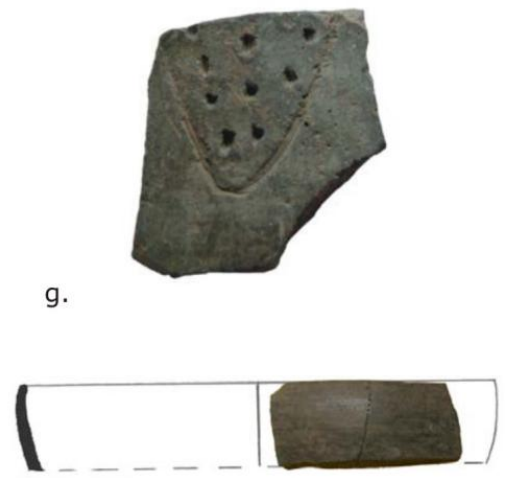

h.
Figura 8. Fragmentos cerámicos recuperados del sector 2 de la terraza al SE del río Zampay. a. b. y e. fragmentos Pulido Negro, Ante y Gris; c. fragmento Alisado Gris Inciso; d. y f. fragmentos Alisado Negro Grabado; $g$. fragmento Pulido Negro con decoración incisa por puntos; h. Puco Pulido (g y h fragmentos de Soria 2 a modo de referencia, tomado de Spano 2008). 


\begin{tabular}{|c|c|c|c|c|c|c|c|c|}
\hline & $\begin{array}{c}\text { SE del Zamp. } \\
\text { Sec. } 1\end{array}$ & $\begin{array}{l}\text { SE del Zamp. } \\
\text { Sec. } 2 \text { Est. } 1\end{array}$ & $\begin{array}{l}\text { SE del Zamp. } \\
\text { Sec. } 2 \text { Est. } 2\end{array}$ & $\begin{array}{l}\text { SE del Zamp. } \\
\text { Sec. } 2 \text { Est. } 3\end{array}$ & $\begin{array}{l}\text { SE del Zamp. } \\
\text { Sec. } 2 \text { Est. } 4\end{array}$ & $\begin{array}{l}\text { SE del Zamp. } \\
\text { Sec. } 3 \text { Est. } 1\end{array}$ & $\begin{array}{l}\text { SE del Zamp. } \\
\text { Sec. } 3 \text { Est. } 2\end{array}$ & Total \\
\hline 1. Alisado & & & & & & & & \\
\hline $\begin{array}{l}\text { Indet. } \\
\text { (no comp) } \\
\text { 2. Alisado }\end{array}$ & 1 & 10 & 11 & 6 & 11 & 7 & 11 & 57 \\
\hline $\begin{array}{l}\text { Indet. } \\
\text { (comp) }\end{array}$ & - & - & - & - & - & - & 1 & 1 \\
\hline 3. Alisado & & & & & & & & \\
\hline $\begin{array}{l}\text { Marrón/ } \\
\text { Anaranjado }\end{array}$ & 29 & - & - & - & - & - & - & 29 \\
\hline $\begin{array}{l}\text { 4. Alisado } \\
\text { Café/ Ante }\end{array}$ & 1 & - & - & - & - & - & - & 1 \\
\hline $\begin{array}{l}\text { 5. Alisado } \\
\text { Negro/Ante }\end{array}$ & - & - & - & 3 & - & - & - & 3 \\
\hline $\begin{array}{l}\text { 6. Alisado } \\
\text { Negro/Rojo }\end{array}$ & - & - & - & - & - & 1 & 2 & 3 \\
\hline $\begin{array}{l}\text { 7. Pulido } \\
\text { Negro }\end{array}$ & - & 1 & - & - & 1 & - & - & 2 \\
\hline 8. Pulido Ante & - & 1 & 1 & 1 & - & - & - & 3 \\
\hline $\begin{array}{l}\text { 9. Pulido Gris } \\
\text { 10. Alisado }\end{array}$ & - & - & 1 & - & - & - & 1 & 2 \\
\hline $\begin{array}{l}\text { Negro } \\
\text { Grabado }\end{array}$ & - & - & 2 & - & - & - & - & 2 \\
\hline $\begin{array}{l}\text { 11. Alisado } \\
\text { Gris Inciso }\end{array}$ & - & - & - & - & 1 & - & - & 1 \\
\hline $\begin{array}{l}\text { 12. Peinado } \\
\text { Con baño }\end{array}$ & - & - & - & 1 & - & - & - & 1 \\
\hline 13. Indet. & - & - & - & 2 & - & - & 2 & 4 \\
\hline Total & 31 & 12 & 15 & 13 & 13 & 8 & 17 & 109 \\
\hline
\end{tabular}

Tabla 3. Fragmentos cerámicos recuperados en la terraza al SE del río Zampay. 5, 6 y 12 cerámica tardía; 3, 4, 7 - 10 cerámica pre- tardía; 1, 2 y 13 indeterminado.

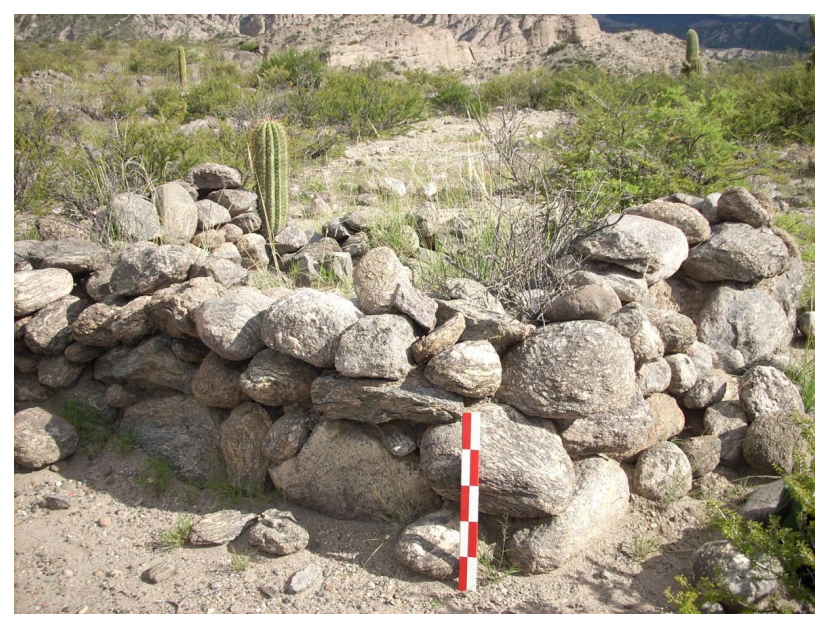

Figura 9. Estructura registrada en el sector 3 de la terraza baja el SE del río Zampay.

corresponderse de manera preliminar con dicho patrón. Por su parte, el conjunto registrado en el sector 2, conformado por recintos de plantas subcuadrangulares y arquitectura expeditiva, podrían responder a corrales o cuadros de cultivos. Las evidencias arqueológicas en Andalhuala Los Andenes, a pesar del desconocimiento sobre su localización, parecen apuntar en la misma dirección, recintos dispersos entre andenes y cuadros de cultivo, sin constituir un núcleo central (Tarragó y Scattolin 1999: 148).

Este patrón de asentamiento de unidades compuestas dispersas en áreas de andenes y cuadros de cultivos en terrenos de poca pendiente y próximos a cursos de agua ha sido registrado en otras localidades del oriente del valle de Yocavil como en el sitio Bajo Los Cardones (Pastor y Rivero 2004), en la Meseta del Agua Salada en Caspinchango (Lanzelotti et al. 2010) y en los yacimientos Pajanguillo Medio y Alto en la localidad de Pajanguillo (Cigliano 1960). Fuera del valle, este patrón con más o menos modificaciones, se repite en los sitios formativos del área de Tafí del Valle (Berberián y Nielsen 1988), en los asentamientos de la Falda occidental del Aconquija (Scattolin 2001; Scattolin y Albeck 1994) y en los sitios Bordo Marcial y Cardonal en el valle del Cajón (Scattolin et al. 2009).

Resumiendo, las evidencias encontradas en la localidad arqueológica de Andalhuala podrían apuntar preliminarmente al sistema de asentamiento definido por Berberián y Nielsen (1988), donde las unidades domésticas consideradas áreas de residencia familiar, almacenaje, procesamiento y consumo de materia/ energía, se encuentran diseminadas en terrenos aptos para la producción agrícola, existan o no estructuras visibles relacionadas con el cultivo ${ }^{8}$ (Soria 2, sector 1 de los terrenos al SE del río Zampay y Andalhuala Los Andenes). Estas áreas de residencia y áreas de producción agrícola se articularían con áreas de producción ganadera localizadas en lugares marginales de los asentamientos,

\footnotetext{
8 Es factible no hallar estructuras agrícolas tempranas debido a los procesos de deterioro que las mismas hayan sufrido, como así también debido a los mencionados procesos de reocupación del espacio.
} 
seguramente en zonas más elevadas cerca de la unión con los faldeos del Aconquija (Sector 2 de los terrenos bajos el SE del río Zampay). Por último, la subsistencia estaría complementada con actividades de caza, recolección y extracción de materias primas en las quebradas que se internan en la sierra. Según los autores, un sistema de asentamiento como este es característico de una sociedad poco densa demográficamente, constituida por unidades domésticas familiares económicamente autosuficientes. Las zonas ocupadas son las más fértiles y requieren por tanto una inversión tecnológica moderada para su aprovechamiento. Por último, la proximidad a otros recursos, como ser pasturas para la caza o la producción pastoril, debieron permitir realizar la totalidad de las actividades de subsistencia mediante un mínimo de desplazamiento (Berberián y Nielsen 1988: 41).

\section{Los paisajes tardíos...}

Para los momentos tardíos, las evidencias indican la reutilización de los mismos espacios, v.g. las terrazas fluviales bajas, a los cuales se suman otros emplazamientos como las lomadas de cumbre plana y los faldeos del Aconquija. La distinción más marcada de los yacimientos según su funcionalidad para los tiempos tardíos permite aplicar como herramienta para el análisis los Tipos de Instalación definidos por Nastri (1997-98).

Como mencionamos, los centros poblados de primera jerarquía parecen haber estado instalados en las lomadas de cumbre plana, formaciones presentes sólo en la vertiente oriental del valle. La LRS, sitio tipo, al presentarse sobre una meseta de pendientes empinadas, se convirtió en uno de los exponentes de pukaras de los tiempos tardíos (Tarragó 2000). Los estilos alfareros encontrados en LRS - estilos San José/ Shiquimil, Loma Rica - parecen indicar un inicio de ocupación temprana dentro del tardío. Remodelaciones posteriores en la plaza oriental y recintos aledaños, indican que la ocupación fue prolongada, al menos de unos 600 años (González y Tarragó 2005). Otro caso de asentamiento sobre meseta de laderas pronunciadas parece constituirlo Andalhuala El Cerro (Arocena y Carnevali 1960). Hasta el momento no contamos con más datos que los brindados por las autoras, quienes dan a entender que El Cerro es un pukara dada la similitud en el emplazamiento y la forma de las habitaciones con el sitio Cerro Mendocino.

En la quebrada de Jujuil, a menos de $8 \mathrm{~km}$ al NE de LRS, se encuentra la mencionada LRJ, confirmando este mismo patrón de instalación (Roldán y Funes 1995). La menor densidad constructiva en comparación con la LRS es lo que llevo a considerarlo yacimiento de segundo rango en la jerarquía de asentamientos (Tarragó 1995). Otros sitios en el valle de Yocavil sobre lomadas o mesetas de cumbre plana, como Yasyamayo (Tarragó 2000), Loma Redonda en San José (González y Tarragó 2005), La Maravilla - Masao en Caspinchango (Baldini y Scattolin 1993) y
Ampajango 2- Rosendo Cáceres en Ampajango (Tarragó y González 2005), muestran evidencias del uso de estas formaciones como áreas de habitación exclusivamente residencial.

Los pukara del período Tardío, emplazados en cerros o mesetas, reflejan la elección de lugares elevados como medio para establecer el vínculo con los antepasados así también como con la fertilidad de la tierra a través de los sembradíos (Tarragó 2000: 291). Así, el pukara como centro social, político y religioso circunscripto y elevado, ejercía un control del espacio agropecuario que se extendía en los terrenos bajos.

La complicada topografía del Sudeste de Yocavil hace que los terrenos disponibles para la producción agrícola no sean abundantes. Esto llevó a una reutilización de las terrazas fluviales bajas para las instalaciones productivas, como se ve reflejado en los primeros cuatro sectores de la Meseta de Andalhuala, en el sector 3 de la terraza al SE del Zampay y en las evidencias que registrara Rex González al pie de la LRS. Hemos planteado que para los tiempos tempranos (época del asentamiento de Soria 2) la Meseta de Andalhuala pudo ser el emplazamiento de un poblado disperso con unidades de vivienda entre campos de cultivos. Para los momentos tardíos, las evidencias parecen indicar un uso con fines productivos dado que las estructuras parecen responder a canchones, andenes y aterrazados y no a un sector residencial exclusivo. Las estructuras de recintos de grandes dimensiones con recintos pequeños circunscriptos en su interior podrían corresponder a unidades habitacionales de las personas dedicadas a las tareas agrícolas. En este sentido, el recinto rectangular con otro pequeño un su interior registrado en el sector 4 se asemeja constructivamente con lo que Tarragó (2007: 18) ha denominado "Cuadrángulo y estructuras anexas en su periferia", registrados en la localidad arqueológica de Rincón Chico, con evidencias de actividades domésticas. En nuestro caso la estructura anexa se encontraría en el interior, pero la presencia de muros dobles con relleno, que suelen adquirir forma monticular al colapsar, y la localización en terrenos bajos próximos al río, son análogos, constituyéndose como una modalidad constructiva típica del paisaje tardío.

Contamos ahora con datos que nos permiten afirmar que los terrenos bajos como la Meseta de Andalhuala constituyeron el núcleo de producción agropecuaria que abastecía, al igual que los terrenos bajos de Entre Ríos/ Shiquimil (Alvarez Larrain 2009a), a la población residencial instalada en lo alto de LRS. Los ríos permanentes Yapes, Andalhuala y Zampay, habrían constituido las fuentes de agua necesarias para la labor agrícola a partir de canales de riego". La distinción planteada aquí entre "Centros poblados" e "Instalaciones productivas" es una primera categorización de los asentamientos para su abordaje

\footnotetext{
9 En marzo de 2010 fueron observados canales de riego en el sector este de la Meseta de Andalhuala.
} 
en esta instancia de las investigaciones ${ }^{10}$. En el caso de la Meseta de Andalhuala, los sectores prospectados parecen indicar una instalación productiva, dada su cercanía a las zonas de explotación económica, siendo la población que la habitaba la encargada de la producción agropecuaria. Sin embargo a futuro, nuevas evidencias podrían indicar la presencia de un centro poblado donde residiera un sector de la población tal vez ligado a otras actividades no directamente agropecuarias, como ser talleres artesanales, tal como fuera registrado en los sitios Rincón Chico 12, 14 y 15 (Tarragó 1998).

La ocupación de los pisos de altura pudo ser constatada también por la presencia de recintos aislados en el Alto de Andalhuala, a 2400 msnm. Scattolin (1994) al estudiar la movilidad ganadera actual en la Falda del Aconquija, registró a lo largo del recorrido de los pastores, campamentos temporarios de pernocte y puestos ganaderos. Mientras los primeros se constituyen a partir de grandes bloques pétreos a los cuales se adosan paredes de pirca, los segundos cuentan ya con corrales y habitaciones a modo de cocina y dormitorio. Nastri pudo registrar en el Cajón puestos arqueológicos con patrones constructivos semejantes (Nastri et al. 2002), reflejando la continuidad en las modalidades constructivas y uso del espacio en los pisos de altura. Esta continuidad se ve reflejada también en la movilidad a través de la sierra. Las alturas del Aconquija son superadas hoy a través de abras y pasos entre sus cumbres (Scattolin y Korstanje 1994: 166), cruces que habrían sido utilizados desde épocas tempranas y luego en el período Tardío para instalar colonias productivas en lugares como Tafí del Valle por parte de los núcleos políticos del valle de Yocavil (Tarragó 1999: 479).

A la luz de estas evidencias, los recintos aislados de planta circular y subcircular y la estructura de grandes dimensiones del sector 2 del Alto de Andalhuala podrían tratarse de puestos de actividades específicas, ligados al pastoreo, siendo los recintos la habitación de los puesteros y la estructura de mayores dimensiones un posible corral. Hemos considerado a los puestos dentro de los tipos de asentamiento de las sociedades tardías, momento en el cual la funcionalidad de los asentamientos parece encontrarse mejor demarcada. Sin embargo, no se elimina la posibilidad de que estas instalaciones hayan sido usadas desde épocas tempranas y reocupadas a lo largo del tiempo, práctica de reclamación que aún perdura. En este sentido la presencia de estilos cerámicos en distintos sectores de la terraza que van desde los tiempos tempranos (cerámica Gris pulida y Negra grabada) hasta los tardíos (Negro/Rojo tipo Loma Rica y fragmento pie de compotera), reflejan el prolongado uso de este espacio en el tiempo.

\footnotetext{
${ }^{10}$ Según lo definiera Nastri (1997-98), los centros poblados son los lugares de habitación del grueso de la población mientras que las Instalaciones productivas están ubicadas en estrecha asociación a las zonas de explotación económica, tanto tierras de cultivo como de pasturas.
}

Por último, cabe mencionar la pequeña estructura de planta circular de 1,34 m de diámetro, registrada sobre un promontorio natural que se eleva por sobre la superficie de la Meseta de Andalhuala. Desconocemos aún qué función pudo haber cumplido esta estructura pero su posición sobre un promontorio natural (posible emulación a menor escala de las montañas del entorno), permite un excelente dominio visual del espacio circundante, motivo por el cual pudo ser empleado en actos de carácter ritual. Tilley (1996) ha mostrado como ciertos rasgos topográficos del paisaje constituyen recursos simbólicos de fuerte significado en la formación de las biografías individuales y en la construcción y reproducción de las estructuras de poder. Así, la construcción de estructuras sobre estos promontorios puede ser interpretado como la demarcación física de un lugar sagrado en el paisaje.

Hemos planteado aquí, de manera preliminar, un acercamiento regional sobre la localidad arqueológica de Andalhuala y la funcionalidad que las distintas evidencias registradas han podido tener en el pasado. Los datos hasta ahora muestran que el Sudeste de Yocavil ha tenido una ocupación prolongada con indicadores de un uso del espacio al menos desde las aldeas agroalfareras del primer milenio D.C. Durante este momento parece haber una elección de los terrenos de fácil acceso que se hallan próximos a los cursos hídricos necesarios para el desarrollo de una agricultura de regadío, característica de zonas semiáridas. Las evidencias también indican ocupaciones posteriores donde los distintos espacios son incorporados a partir de una variabilidad formal de asentamientos. Así, para los tiempos tardíos los terrenos bajos continúan habitados, seguramente por necesidades productivas. Se le suman a estos las mesetas altas de cumple plana, con un claro uso habitacional/doméstico y con funciones político- religiosas y los faldeos bajos del Aconquija, para la instalación de puestos de actividades específicas. Si bien resta mucho por hacer, datos generados recientemente, en proceso de análisis y futuros trabajos en el área, permitirán seguir reconstruyendo estos distintos paisajes arqueológicos producto de las distintas racionalidades de las sociedades que habitaron Andalhuala en el pasado.

Buenos Aires, 15 de Junio 2010

\section{Agradecimientos}

Deseo agradecer a la familia Soria de Andalhuala por su siempre afectuoso recibimiento. También a Fernando Cabrera y Juan Pablo Carbonelli por su colaboración y compañía durante la campaña emprendida en marzo del 2008 que hicieron posible este trabajo. Especialmente a Myriam Tarragó por la lectura del manuscrito y sus significativos aportes. Por último a los evaluadores anónimos cuyas críticas mejoraron sin duda este trabajo. No obstante todo lo escrito es de mi entera responsabilidad. 


\section{Bibliografía}

Álvarez Larrain, A. 2009a. Sudeste del valle de Yocavil: Teledetección y paisajes arqueológicos. Trabajo presentado en las VIII Jornadas de Jóvenes Investigadores en Ciencias Antropológicas. INAPL, Buenos Aires. En prensa.

Álvarez Larrain, A. 2009b. "Teledetección y análisis del uso del espacio en el sudeste del valle de Yocavil (Dpto. de Santa María, Prov. de Catamarca)". Facultad de Filosofía y Letras, UBA, Argentina, 208 páginas. Museo Etnográfico.

Álvarez Larrain, A. 2009c. Variabilidad en la construcción y el uso de los paisajes arqueológicos en el valle de Andalhuala y aledaños, valle de Santa María, Catamarca. Proyecto aprobado para el Doctorado en Arqueología de la Universidad de Buenos Aires, ms. Museo Etnográfico.

Álvarez Larrain, A., J. Baigorria di Scala, C. Bellotti, J. P. Carbonelli, S. Grimoldi, S. López, D. Magnifico, V. Palmarczuk, R. Spano, G. Spengler, L. Stern Gelman y F. Weber. 2009. Avances en el estudio de un contexto doméstico formativo en el Valle de Yocavil. T. Bourlot, D. Bozzuto, C. Crespo, A.C. Hecht y N. Kupersmit (Eds.), Entre pasados y presentes II, Estudios contemporáneos en Ciencias Antropológicas: 369-383, Vázquez Mazzini Editores, Buenos Aires.

Ambrosetti, J. B. 1897. La antigua ciudad de Quilmes (valles Calchaquíes). Boletín del Instituto Geográfico Argentino 18: 33-70.

Anschuetz, K. F., R. H. Wilshusen y C. L. Scheick. 2001. An Archaeology of Landscapes: Perspectives and Directions. Journal of Archaeological Research 9, 2: 152- 197.

Arocena, M. L. y B. Carnevali. 1960. Andalhuala. E. Cigliano (dir.), Investigaciones Arqueológicas en el Valle de Santa María. Publicación 4: 53- 63. Instituto de Antropología, Facultad de Filosofía y Letras, Universidad Nacional del Litoral. Rosario.

Baldini, L. y M. C. Scattolin. 1993. El sitio Masao. Nota acerca de su identificación. Revista del Museo de Historia Natural de San Rafael XII, 2: 47- 62.

Belotti López de Medina, C. 2007. Consumo de camélidos en el Valle de Yocavil (pcia. de Catamarca) a inicios del Período Formativo, fines del primer milenio A.C.: zooarqueología del sitio Soria 2 . Libro de resúmenes extendidos del XVI Congreso Nacional de Arqueología Argentina, III: 85-89, San Salvador de Jujuy.

Berberián, E. y A. Nielsen. 1988. Sistemas de asentamiento prehispánicos en la etapa Formativa del valle de Tafí. (Pcia. De Tucumán- República Argentina. E. Berberián (Ed.), Sistemas de asentamiento prehispánicos en el valle de
Tafi: 21- 51, Editorial Comechingonia, Córdoba.

Bolsi, A. 1967. Estudio antropogeográfico del valle de Santa María, Catamarca. Ed. Departamento de extensión Universitaria y Ampliación de Estudios, Universidad Nacional del Noreste, Resistencia.

Boman, E. 1908. Antiquités de la Región Andine de la République Argentine et du désert d'Atacama. Tomo I, Impprimierie Nacionales, París.

Bruch, C. 1911. Exploraciones arqueológicas en las provincias de Tucumán y Catamarca. Revista del Museo de la Plata XIX.

Bugliani, F. 2008. Consumo y representación en el Formativo del sur de los Valles Calchaquíes (Noroeste argentino). Los conjuntos cerámicos de las aldeas del primer milenio AD. South American Archaeology Series 2. BAR International Series 1774, Oxford.

Carbonelli, J.P. 2009. "Interacciones cotidianas entre materias primas y sujetos sociales en el Valle de Yocavil. El caso del sitio Soria 2 (Andalhuala, Pcia. de Catamarca)". Facultad de Filosofía y Letras, UBA, Argentina, 144 páginas. Museo Etnográfico.

Chiappe, D. H. 1965. "Estudio arqueológico de la Colección Methfessel del Museo de La Plata". Facultad de Ciencias Naturales, UNLP, Argentina, 81 Páginas, Museo Etnográfico.

Cigliano, E. M. (dir.). 1960. Investigaciones Arqueológicas en el Valle de Santa María. Publicación del Instituto de Antropología, Publicación 4, Facultad de Filosofía y Letras, Universidad Nacional del Litoral, Rosario.

Clarke, D. L. 1977. Spatial Archaeology. Academic Press, London.

Copello, R. 1991. "Loma Alta de Shiquimil. Instalaciones agrícolas y fuentes hídricas. Prospección del Lic. Sergio Caviglia". ms. Museo Etnográfico.

Criado Boado, F. 1993. Límites y posibilidades de la arqueología del Paisaje. Revista de Prehistoria y Arqueología 2: 9- 55.

Criado Boado, F. 1995 (1991). Construcción social del espacio y reconstrucción arqueológica del paisaje. C. Barros y J. Nastri (Comp.), La perspectiva espacial en arqueología: 75- 116, Centro Editor de América Latina, Buenos Aires.

Criado Boado, F. 1999. Del terreno al espacio: planteamientos y perspectivas para la Arqueología del Paisaje. CAPA 6: 1- 77.

http://www-gtarpa.usc.es/descarga/CapaTapa/CAPA/ 
CAPA6.pdf (Última consulta: 10/06/2010)

González, A. R. 1954. Las ruinas de Loma Rica y alrededores. Publicaciones Técnicas de Natura 5, 1: 75-90.

González, L. R. y M. N. Tarrago. 2005. Vientos del Sur. El valle de Yocavil (Noroeste argentino) bajo la dominación incaica. Estudios Atacameños 29: 67- 95.

Hodder, I. y C. Orton. 1990. (1976). Análisis espacial en arqueología. Crítica, Barcelona.

Ingold, T. 1993. The temporality of the landscape. World Archaeology, XXV, 2: 152- 174.

Kusch, F., A. Callegari e I. Gordillo. 2001. Arqueología del Paisaje. Arqueología 11: 251- 259.

Lanzelotti, S., A. Álvarez Larrain, M. Lamamí, G. Acuña. 2010. La espacialidad en Caspinchango: primera aproximación a la distribución de conjuntos arquitectónicos en la "Mesada del Agua Salada". Libro de resúmenes extendidos del XVII Congreso Nacional de Arqueología Argentina, Mendoza. En prensa.

Liberani, I. y R. Hernández. 1877. Excursión Arqueológica en los Valles de Santa María, Catamarca. Publicación $\mathrm{N}^{\circ}$ 563. Instituto de Arqueología de la Universidad Nacional de Tucumán, San Miguel de Tucumán.

Mc Cormac, F. G., A. G. Hogg, P. G. Blackwell, C. E. Buck, T. F. G. Higham y P. J. Reimer. 2004. SHCal04 Southern Hemisphere calibration, 0-11.0 cal kyr BP. Radiocarbon 46 (3): 1087-1092.

Mañana Borrazás, P., R. Blanco Rotea y X. Ayán Villa. 2002. Arqueotectura 1: Bases teórico metodológicas para una Arqueología de la Arquitectura, TAPA 25: 11-18. http://www-gtarpa.usc.es/descarga/CapaTapa/Tapa/ TAPA25.pdf (Última consulta: 10/06/2010).

Marchegiani, M. 2008. Estilo y cronología. Los cambios en la cerámica funeraria de Rincón Chico entre los siglos X y XVII DC. M. Tarragó y L. González (ed.), Estudios arqueológicos en Yocavil, Cap. IV: 127- 175, Asociación de amigos del Museo Etnográfico, Buenos Aires.

Marchegiani, M. y C. Grieco. 2007. Tecnología, estilo y cronología de la cerámica ordinaria de Rincón Chico, Valle de Yocavil, Catamarca. Libro de resúmenes extendidos del XVI Congreso Nacional de Arqueología Argentina, tomo II: 201-206, San Salvador de Jujuy.

Marchegiani, M., V. Palamarczuk y A. Reynoso. 2009. Las urnas negro sobre rojo tardías de Yocavil (Noroeste argentino). Reflexiones en torno al estilo. Boletín del Museo Chileno de Arte Precolombino 14, 1: 69- 98.
Nastri, J. H. 1997- 1998. Patrones de asentamiento prehispánicos tardíos en el Sudoeste del Valle de Santa María (Noroeste argentino). Relaciones de la Sociedad Argentina de Antropología XXI- XXIII: 247- 270.

Nastri, J. H. 2001. Interpretando al describir: la arqueología y las categorías del espacio aborigen en el valle de Santa María. Revista Española de Antropología Americana 31: 31- 58.

Nastri, J. H. 2003. Aproximaciones al espacio calchaquí. P. Cornell y P. Stenborg (editores), Local, Regional, Global: prehistoria, protohistoria e historia en los Valles Calchaquíes, Anales Nueva Época N 6: 99-125, Instituto Iberoamericano - Universidad de Göteborg, Göteborg.

Nastri J. H., G. Pratolongo, G. Caruso, M. Hopczak y M. Maniasiewicz. 2002. Los puestos prehispánicos de la Sierra del Cajón (Provincia de Catamarca). Actas del XIII Congreso Nacional de Arqueología Argentina, Tomo II: 421-430. Córdoba.

Orejas, A. 1991. Arqueología del Paisaje: Historia, problemas y perspectivas. Archivo Español de Arqueología 64: $191-230$.

Palamarczuk, V., R. Spano, F. Weber, D. Magnífico, S. López y M. Manasiewicz. 2007. Soria 2. Apuntes sobre un sitio Formativo en el valle de Yocavil (Catamarca, Argentina). Intersecciones en Antropología 8: 121-134.

Pastor, S. y D. E. Rivero. 2004. Nuevas evidencias en torno a la ocupación agroalfarera temprana del valle de Yocavil. M. Carballido Calatayud (ed.), Mosaico. Trabajos en Antropología Social y Arqueología: 189-199, Fundación Historia Natural "Félix de Azara", INAPL, Universidad CAECE, Buenos Aires.

Perrotta, E. y C. Podestá. 1978. Contribution to the San José and Santa María Cultures, Northwest Argentina. D. Browman (Ed.), Advances in Andean Archaeology: 525551, Mouton, París.

Piñeiro, M. 1997. “La producción cerámica especializada. Desarrollo tecnológico e implicancias socio-económicas a partir del estudio de la variabilidad individual en los restos materiales. ms, Museo Etnográfico.

Quiroga, A. 1931. Petrografías y Pictografías de Calchaquí. Imprenta UBA, Buenos Aires.

Raffino, R. A. 1991. Poblaciones indígenas en Argentina. Ed. TEA, Buenos Aires.

Rapoport, A. 1972. (1969). Vivienda y Cultura. Editorial Gustavo Gili, Barcelona.

Roldán, M. y M. Funes. 1995. El espacio doméstico 
de Loma Rica de Jujuil (Dpto. de Santa María, Pcia. Catamarca). Comechingonia 8: 97- 123.

Ruiz Huidrobo, O. J. 1972. Descripción geológica de la hoja 11e, Santa María. Boletín No 134. Ministerio de Industria y Minería, Subsecretaría de Minería, Servicio Nacional Minero Geológico, Buenos Aires.

Scattolin, M. C. 1994. El circuito ganadero en el Aconquija. Revista de la Escuela de Antropología 2: 99-109.

Scattolin, M. C. 2000. Santa María durante el Primer Milenio A. D. ¿Tierra baldía?. Arstryck 1995- 1998: 63- 83.

Scattolin, M. C. 2001. Organización residencial y arquitectura en el Aconquija durante el primer milenio A. D. Actas del XIII Congreso Nacional de Arqueología Argentina I: 439- 449, Córdoba.

Scattolin, M. C. 2003. Los ancestros de Calchaquí: una visión de la colección Zavaleta. Cuadernos N²0: 51-79.

Scattolin, M. C. y M. E. Albeck. 1994. El asentamiento humano en la falda occidental del Aconquija

(Catamarca, Argentina). Shincal 4: 35- 65.

Scattolin, M. C., F. Bugliani, L. Cortés, C. Calo, L. Pereyra Domingorena y A. Izeta. 2009. Pequeños mundos: hábitat, maneras de hacer y afinidades en aldeas del valle del Cajón, Catamarca. Relaciones de la Sociedad Argentina de Antropología XXXIV: 251-274.

Scattolin, M. C. y M. A. Korstanje. 1994. Tránsito y frontera en los Nevados del Aconquija. Arqueología 4: 165-197.

Spano, R. 2008. "Indagaciones sobre las sociedades aldeanas del valle de Yocavil; análisis de la alfarería fina del sitio Soria 2 (Andalhuala, Provincia de Catamarca)". Facultad de Filosofía y Letras, UBA, Argentina. 182 páginas. Museo Etnográfico.

Tarragó, M. N. 1987. Sociedad y sistema de asentamiento en Yocavil. Cuadernos del Instituto Nacional de Antropología, 12: 179- 196.

Tarragó, M. N. 1995. Desarrollo Regional en Yocavil. Una estrategia de investigación. Actas del XIII Congreso Nacional de Arqueología Chilena, I: 225- 235, Antofagasta de la Sierra.

Tarragó, M. N. 1998. El patrimonio del valle de Santa María en peligro. El Rincón Chico. 50 años de aportes al desarrollo y consolidación de la antropología argentina. Homenaje a Alberto Rex González: 205-253, Facultad de
Filosofía y Letras - Fundación Argentina de Antropología, Buenos Aires.

Tarragó, M. N. 1999. Las sociedades del Sudeste andino. T. Rojas Rabiela y J. Murra (Ed.), Las sociedades originarias. Historia General de América Latina I, cap. XIX: 465-480, Ed. Trotta, Ediciones UNESCO, París.

Tarragó, M. N. 2000. Chacras y pukaras. Desarrollos sociales tardíos. M. N. Tarragó (Ed.), Nueva Historia Argentina, Los pueblos originarios y la conquista I, Cap. VII: 257- 300, Sudamericana, Buenos Aires.

Tarragó, M. N. 2007. Ámbitos domésticos y de producción artesanal en el Noroeste Argentino prehispánico. Intersecciones en Antropología 8:87-100.

Tarragó, M. N., S. Caviglia, M. Peralta Sanhuesa y J. Sosa. 1988. Los grupos cerámicos del poblado de Loma Rica de Shiquimil, Catamarca Argentina. Ponencia presentada en el IX Congreso Nacional de Arqueología Argentina, Ms, Museo Etnográfico.

Tarragó, M. N. y L. González. 2005. Variabilidad en los modos arquitectónicos incaicos. Un caso de estudio en el Valle de Yocavil (Noroeste Argentino). Chungara, Revista de Antropología Chilena 37: 129- 143.

Tarragó, M. N. y J. H. Nastri. 1999. Dimensiones de la complejidad santamariana. Actas del XII Congreso Nacional de Arqueología Argentina, II: 259-264, La Plata.

Tarragó, M. N. y M. C. Scattolin. 1999. La problemática del Período Formativo en el valle de Santa María. Actas del XII Congreso Nacional de Arqueología Argentina, I: 142- 153, La Plata.

Ten Kate, H. 1894. Rapport sommaire sur une excursion archeologique dans les provinces de Catamarca, Tucumán et Salta. Revista del Museo de La Plata 5: 329-348.

Tilley, C. 1996. The power of rocks: topography and monument construction on Bodmin Moor. World Archaeology 28, 2: 161- 176.

Trigger, B. G. 1992. (1989) Historia del pensamiento arqueológico. Crítica, Barcelona.

Weiser, V. 1923- 24. "Notas y diario de viaje de las expediciones arqueológicas de Benjamín Muñiz Barreto". ms, Museo de La Plata.

Willey, G. 1953. Prehistoric settlement pattern in the Virú Valley, Perú. Bulletin 155. Bureau of American Ethnology. Washington. 